\title{
Investigations on the influence of phosphonates in dispersing iron oxide (rust) by polymeric additives for industrial water applications
}

\author{
Z. Amjad \\ Division of Mathematics and Sciences, Walsh University, 2020 E. Maple Street, N. Canton, \\ Ohio 44270, USA \\ E-mail: zamjad@walsh.edu
}

\begin{abstract}
The performance of polymeric and non-polymeric additives as iron oxide (rust) dispersants in aqueous system has been investigated. The polymers evaluated include: homopolymers of acrylic acid, aspartic acid; copolymers of acrylic acid:vinyl acetate; acrylic acid: hydroxylpropyl acrylate, maleic acid: sulfonated styrene; and terpolymer of acrylic acid:2acrylamido-2-methyl propane sulfonic acid:sulfonated styrene. Phosphonates (or nonpolymeric additives) tested include: hydroxyphosphono acetic acid, HPA; aminotris(methylenephosphonic acid), AMP; hydroxyethylidene 1,1-diphosphonic acid, HEDP; 2-phosphonobutane 1,2,4-tricarboxylic acid, PBTC; and polyamino polyether methylene phosphonic acid, PAPEMP. Based on the performance data, polymers effectiveness as iron oxide dispersants is: terpolymer $>$ copolymer $>$ homopolymer. Under similar experimental conditions, phosphonates exhibit poor performance as iron oxide dispersants. It has also been observed that presence of phosphonates exhibit antagonistic effect on the performance of polymers.
\end{abstract}

Keywords: iron oxide, rust, dispersion, polymers, phosphonates.

Received: January 21, 2014.

doi: $\underline{10.17675 / 2305-6894-2014-3-2-089-100}$

\section{Introduction}

Deposition of unwanted materials on equipment surfaces in one of the major problem in the efficient operation of geothermal, oil and gas production, desalination and other water treatment installations. The deposits generally consist of: $a$ ) mineral scale, e.g., carbonate, sulfate, and phosphate salts of alkaline earth metals; $b$ ) suspended matter, e.g., clay, silt, corrosion products; $c$ ) microbiological; and $d$ ) process contaminants. The problems caused by deposits include: obstruction of fluid flow, impedance of heat transfer, wear of metal parts, localized corrosion attack, unscheduled equipment shutdown, and expensive cleaning costs [1].

Metal ions (e.g., $\mathrm{Al}, \mathrm{Cu}, \mathrm{Mn}, \mathrm{Fe}, \mathrm{Zn}$ ) present in the feed water may get oxidized by oxidizing biocides and/or may form insoluble oxide/hydroxide salts such as $\mathrm{Al}(\mathrm{OH})_{3}$, $\mathrm{Cu}(\mathrm{OH})_{2}, \mathrm{Fe}(\mathrm{OH})_{3}, \mathrm{Zn}(\mathrm{OH})_{2}$, and $\mathrm{MnO}_{2}$. Maintaining these hydrolyzed and/or oxidized 
metal ions in soluble and dispersed forms can prevent the buildup of unwanted deposits on various substrates. Iron based deposits typically are in the form of $\mathrm{FeO}, \mathrm{Fe}_{2} \mathrm{O}_{3}, \mathrm{Fe}_{3} \mathrm{O}_{4}, \mathrm{FeS}$, iron silicate, etc. Often manganese is also detected in these deposits. Iron fouling occurs as a result of corrosion processes throughout the system. Thus, it is very important to implement a good corrosion control program.

Iron-based fouling generally occurs in desalination and industrial cooling water systems as a result of carryover from clarifiers, where iron salts may be used as coagulants or where raw water (i.e., well water) may be high in iron. Iron levels of $2 \mathrm{ppm}$ (parts per million) or greater in circulating water may be controlled by incorporating a dispersant into the water treatment formulation. In cooling waters, $\mathrm{Fe}_{2} \mathrm{O}_{3}$ (hematite) and $\mathrm{FeOOH}$ are the two most common iron deposits. Magnetite $\left(\mathrm{Fe}_{3} \mathrm{O}_{4}\right)$ is rarely encountered in cooling systems. Magnetite needs high temperature and anaerobic conditions. Most magnetite found in cooling systems arrives via airborne or waterborne solids.

Suspended matter commonly encountered in industrial water systems generally carries a slight negative charge. The type, size, and concentration of suspended matter affect their behavior in water systems. Therefore, anionic polymers are normally the most efficient dispersants because these anionic polymers increase the negative surface charge and keep particles in suspension. The dispersion is generally defined as a suspension of insoluble particles formed either through de-flocculation, that is, breaking down of agglomerated particles, or from the stabilization of small suspended particles. The solid/liquid dispersion technology has many domestic and industrial applications. The suspension of particulate matter by detergents for their removal in the rinse cycle of washing machines is a practical example. Industrial applications of dispersant technology include paints, inks, cosmetics, and paper manufacturing.

Suspension of clays, metal oxides, pigments, ceramic materials, and other insoluble particulate solids in aqueous systems through the use of small quantities of synthetic polymers, polyphosphates, and other polyelectrolytes has become an increasingly important area of study with high technological relevance. Garris and Sykes [2] in their study on the evaluation of a variety of polyamino acid analogs of biomineral proteins as dispersants for various substrates, e.g., clay, calcium carbonate, calcium phosphate, iron oxide, reported that performance of these dispersants was comparable to synthetic polymeric dispersants. In another study by Dubin [3], it was shown that acrylic acid and maleic acid based polymers performed better than polyphosphates and phosphonates as iron oxide dispersants. Bain et al. [4] tested the performance of poly(aspartic acid), PAS, as dispersant for kaoline clay. Results of their study show that low molecular weight (MW) PAS performed better than poly(acrylic acid), PAA, in dispersing clay in aqueous system. In another study, Amjad [5] in his study on the evaluation of a variety of polymeric dispersants reported that polymer architecture plays an important role in dispersing iron oxide particles in aqueous systems. Similar observations were also reported by Amjad and Zuhl [6] in their studies on the dispersion of clay, hydroxyapatite, and silica. 
During the last two decades the evaluation of polymeric and non-polymeric additives as scale inhibitors, dispersants, and metal ions stabilizing agents for cooling water, boiler, geothermal, oil and gas production, and desalination processes has been the subject of numerous investigations [7-10]. Results of these studies reveal that whereas homopolymers of acrylic acid, maleic acid, aspartic acid, and itaconic acid are effective scale inhibitors, these additives exhibit poor performance as iron oxide dispersants [5]. Acrylic acid and/or maleic acid based copolymers, on the other hand, have been shown to be excellent inhibitors for calcium phosphate and calcium phosphonate scales, and are also effective dispersants but show mediocre performance as inhibitors for $\mathrm{CaCO}_{3}, \mathrm{BaSO}_{4}$, and $\mathrm{CaSO}_{4} \cdot 2 \mathrm{H}_{2} \mathrm{O}$ scales [11-13]. Results of studies on the evaluation of non-polymeric additives, i.e., polyphosphates, phosphonates, etc., as scale inhibitors and dispersant reveal that these additives are excellent scale inhibitors but show poor performance as dispersant for various substrates [14-16]. The present study is concerned with the impact of phosphonates on the performance of copolymers commonly used as dispersants in water treatment formulations. Additionally, optical microscopy was used to study the impact of phosphonates and copolymers on de-agglomeration of iron oxide particles.

\section{Experimental}

\section{Materials}

Grade A glassware and analytical grade chemicals were used. Stock solutions of calcium chloride, sodium sulfate, sodium bicarbonate and sodium carbonate were prepared from the respective crystalline solids (Merck) using distilled water, filtered through $0.22 \mu \mathrm{m}$ filter paper and standardized as described previously [5]. Iron oxide $\left(\mathrm{Fe}_{2} \mathrm{O}_{3}\right)$ used in this investigation was obtained from Fisher Scientific Co. Powder X-ray diffraction showed that it consisted exclusively of $\alpha-\mathrm{Fe}_{2} \mathrm{O}_{3}$ (hematite). The polymers tested were laboratory preparations and commercial materials. Polymer stock solutions were prepared on a dry weight basis. The desired concentrations of the polymers were obtained by dilution. Table 1 lists the polymers and phosphonates tested.

A known amount $(0.12 \mathrm{~g})$ of iron oxide was suspended in a $800 \mathrm{~mL}$ beaker containing $600 \mathrm{~mL}$ of simulated industrial water with a known polymer concentration (dispersant). The simulated industrial water was prepared by mixing accurately measured volumes of standard solutions of $\mathrm{CaCl}_{2}, \mathrm{MgCl}_{2}, \mathrm{Na}_{2} \mathrm{SO}_{4}$, and $\mathrm{NaHCO}_{3}$. The composition of the simulated industrial water was: $100 \mathrm{mg} / \mathrm{L} \mathrm{Ca}, 30 \mathrm{mg} / \mathrm{L} \mathrm{Mg}, 314 \mathrm{mg} / \mathrm{L} \mathrm{Na}, 571 \mathrm{mg} / \mathrm{L} \mathrm{Cl}$, $192 \mathrm{mg} / \mathrm{L} \mathrm{SO}_{4}, 60 \mathrm{mg} / \mathrm{L} \mathrm{HCO}_{3}$. The $\mathrm{pH}$ of the simulated water was 7.6-7.8. All dispersion experiments were done at room temperature $\left(\sim 22^{\circ} \mathrm{C}\right)$.

In a typical test, six experiments were run simultaneously using a gang-stirrer at 110 revolutions per minute (superficial fluid velocity $1.22 \mathrm{~ms}^{-1}$, or for the experimental setup the Reynolds number was 9778) [17]. At known time intervals transmittance readings (\%T) were taken with a Brinkmann ${ }^{\circledR}$ Probe Colorimeter equipped with a $420 \mathrm{~nm}$ filter. The absorbance of several filtered $(0.22 \mu \mathrm{m})$ suspensions with low to high $\% T$ was measured at $420 \mathrm{~nm}$. It was 
found that absorbance contribution due to dissolved species was insignificant $(<3 \%)$. Polymer performance as percent iron oxide dispersed $(\% D)$ was calculated, after making correction for the $\% T$ reading obtained in the absence of polymer $(90 \% T)$, from $\% T$ readings $(\% D=100-$ $1.1 \% T)$ measured past $3 \mathrm{~h}$ from the preparation of the solutions and was expressed as the amount of iron oxide dispersed. The data presented in this study were reproducible $( \pm 5 \%$ or better). The performance of the polymer was determined by comparing the $\% D$ values of the slurries containing polymers against control (no polymer). Higher $\% D$ values suggested that the dispersion was more effective. The following ranking was assigned for dispersant performance: Poor $(<25 \% D)$, Mediocre $(<50 \% D)$, Good $(<75 \% D)$, Excellent $(>85 \% D)$.

Table 1. Polymers and phosphonates evaluated.

\begin{tabular}{|c|c|c|c|c|}
\hline Additive & $\begin{array}{l}\text { Functional } \\
\text { Group }\end{array}$ & $\begin{array}{c}\text { Ionic } \\
\text { Charge* }\end{array}$ & $\begin{array}{l}\text { Molecular } \\
\text { Weight }\end{array}$ & Acronym \\
\hline Poly(maleic acid:sulfonated styrene) & $\begin{array}{c}-\mathrm{COOH} \\
-\mathrm{SO}_{3} \mathrm{H}\end{array}$ & $\begin{array}{l}\text { Anionic } \\
\text { Anionic }\end{array}$ & $<10,000$ & $\mathrm{P} 1$ \\
\hline Poly(acrylic acid: hydroxypropyl acrylate) & $\begin{array}{l}-\mathrm{COOH} \\
-\mathrm{COOR}\end{array}$ & $\begin{array}{l}\text { Anionic } \\
\text { Non-ionic }\end{array}$ & $\sim 10,000$ & $\mathrm{P} 2$ \\
\hline Poly(acrylic acid:vinyl acetate) & $\begin{array}{c}\mathrm{COOH} \\
-\mathrm{COOR}\end{array}$ & $\begin{array}{l}\text { Anionic } \\
\text { Non-ionic }\end{array}$ & $\sim 9,000$ & P3 \\
\hline $\begin{array}{l}\text { Poly(acrylic acid:2-acrylamido-2-methyl } \\
\text { propane sulfonic acid: sulfonated styrene) }\end{array}$ & $\begin{array}{l}-\mathrm{COOH} \\
-\mathrm{SO}_{3} \mathrm{H}\end{array}$ & $\begin{array}{l}\text { Anionic } \\
\text { Anionic }\end{array}$ & $<10,000$ & P4 \\
\hline Poly(aspartic acid) & $-\mathrm{COOH}$ & Anionic & $<20,000$ & P5 \\
\hline Poly(acrylic acid) & $-\mathrm{COOH}$ & Anionic & $\sim 3,000$ & P6 \\
\hline Poly(methacrylic acid) & $-\mathrm{COOH}$ & Anionic & $\sim 6,000$ & $\mathrm{P} 7$ \\
\hline Carboxymethyl inulin-COOH (25\%) & $\begin{array}{l}-\mathrm{COOH} \\
\text { saccharide }\end{array}$ & $\begin{array}{l}\text { Anionic } \\
\text { Non-ionic }\end{array}$ & 4,500 & P8 \\
\hline Hydroxyphosphono acetic acid & $\begin{array}{c}-\mathrm{COOH} \\
-\mathrm{PO}_{3} \mathrm{H}_{2} \\
-\mathrm{OH}\end{array}$ & $\begin{array}{c}\text { Anionic } \\
\text { Anionic } \\
\text { Non-ionic }\end{array}$ & 156 & HPA \\
\hline Aminotris(methylene phosphonic acid) & $-\mathrm{PO}_{3} \mathrm{H}_{2}$ & Anionic & 299 & AMP \\
\hline Hydroxyethylidene 1,1-diphosphonic acid & $\begin{array}{l}-\mathrm{PO}_{3} \mathrm{H}_{2} \\
-\mathrm{OH}\end{array}$ & $\begin{array}{l}\text { Anionic } \\
\text { Non-ionic }\end{array}$ & 206 & HEDP \\
\hline $\begin{array}{l}\text { 2-phosphonobutane 1,2,4-tricarboxylic } \\
\text { acid }\end{array}$ & $\begin{array}{r}-\mathrm{COOH} \\
-\mathrm{PO}_{3} \mathrm{H}_{2}\end{array}$ & $\begin{array}{l}\text { Anionic } \\
\text { Anionic }\end{array}$ & 270 & PBTC \\
\hline Polyether polyamino phosphonic acid & $\begin{array}{c}-\mathrm{PO}_{3} \mathrm{H}_{2} \\
-\mathrm{O}-\text { (ether) }\end{array}$ & $\begin{array}{l}\text { Anionic } \\
\text { Non-ionic }\end{array}$ & $600-630$ & PAPEMP \\
\hline
\end{tabular}

*pH of work solution. 


\section{Results and Discussion}

\section{Performance of polymers}

Dispersion time: Results of iron oxide dispersancy collected in the presence of $1.0 \mathrm{ppm}$ of copolymer P1 (maleic acid:sulfonated styrene) as a function of time are illustrated in Fig. 1. As seen in Fig. 1, percent dispersancy $(\% D)$ increases with increasing time. For example, $\% D$ value obtained at $0.5 \mathrm{~h}$ in the presence of $1.0 \mathrm{ppm} \mathrm{P} 1$ is $51 \%$. As noted in Fig. 1, increasing the dispersion time by a factor of two, i.e., from $0.50 \mathrm{~h}$ to $1.0 \mathrm{~h}$, results in $\sim 13 \%$ increase (from 51 to $64 \%$ ) in $\% D$ value. The data presented in Fig. 1 also reveal that $\% D$ value gradually increases with increase in dispersion time and reaches a maximum value $\sim 3 \mathrm{~h}$. It is also evident from Fig. 1 that further increase in dispersion time, i.e., from $3 \mathrm{~h}$ to $4 \mathrm{~h}$, only results in $\sim 2 \%$ increase in $\% D$ value. As noted in Fig. 1 , similar $\% D v s$. time profile was also observed for homopolymer of aspartic acid, P5. Based on these observations, $3 \mathrm{~h}$ time was selected as a criterion for comparing the performance of dispersant. Thus, it is evident from Fig. 1 that dispersion time (i.e., polymer contact time with iron oxide particles) plays an important role in dispersing iron oxide in aqueous solution. It should be noted that similar dispersion time dependence of polymer performance has also been reported for hydroxyapatite [18].

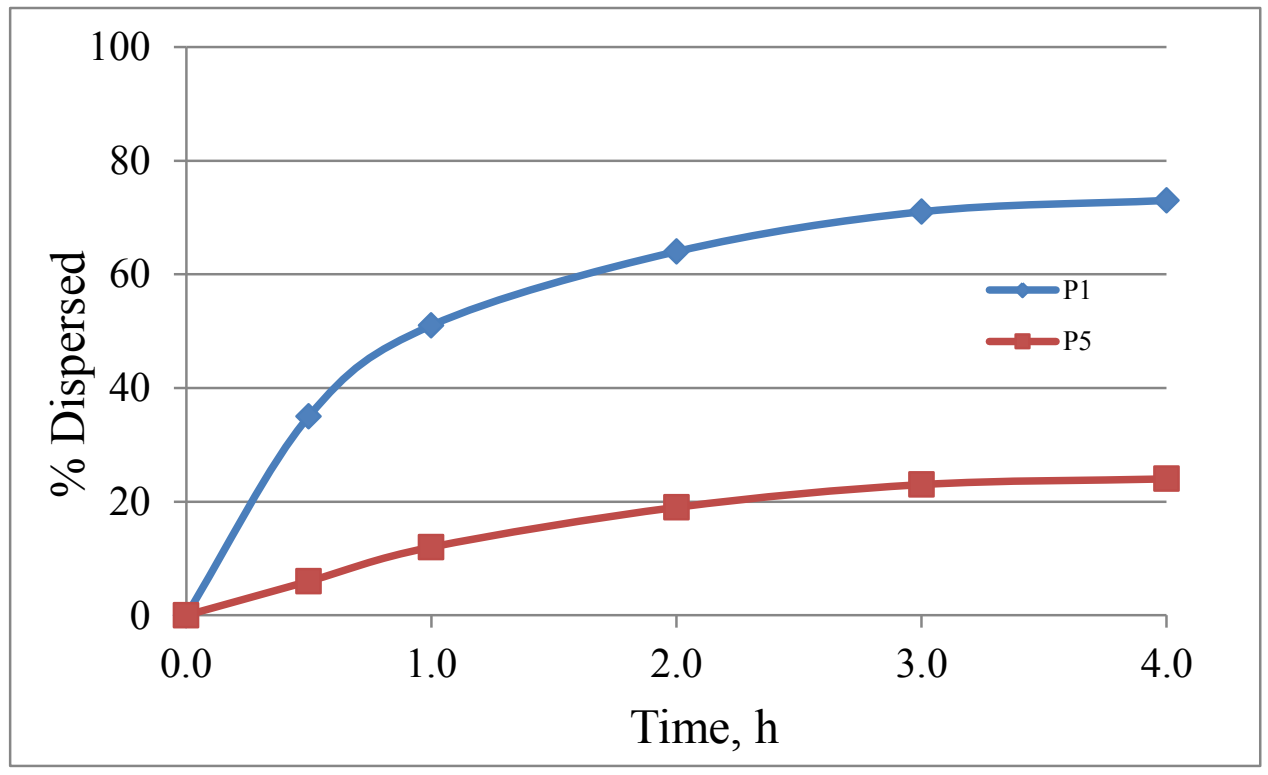

Figure 1. Iron oxide dispersion in the presence of $1.0 \mathrm{ppm} \mathrm{P1}$ and P5 and as a function of time.

Polymer dosage: The impact of polymer dosage on iron oxide dispersion was also studied. Results presented in Fig. 2 show that P1 performance as iron oxide dispersant strongly depends on polymer dosage. For example, $\% D$ values obtained at $3 \mathrm{~h}$ in the presence of 0.25 and $0.50 \mathrm{ppm}$ of $\mathrm{P} 1$ are 22 and $35 \%$, respectively. As may be seen, in all cases the extent of dispersion of iron oxide particles does not depend linearly on the amount of polymer added. Thus, increasing P1 concentration two fold (i.e., from 0.50 to $1.0 \mathrm{ppm}$ ) 
resulted in only $\sim 17 \%$ increase (from 54 to $71 \%$ ) in $\% D$ value. This is not surprising, if we take into account that the extent of adsorption depends largely on the conformation of the polymer on the particles. More detailed studies on the mechanism of adsorption through the respective adsorption isotherms is needed to obtain a better understanding of this behavior of the polymers. The data presented in Figs. 1 and 2 clearly show that polymer performance as iron oxide dispersant depends on both the dispersion time and the polymer concentration. The time dependence of the dispersion in the presence of tested polymers is an indication of the rather slow kinetics of adsorption of the polymers on the suspended particles with the concomitant changes of distribution of charges in the electrical double layer.

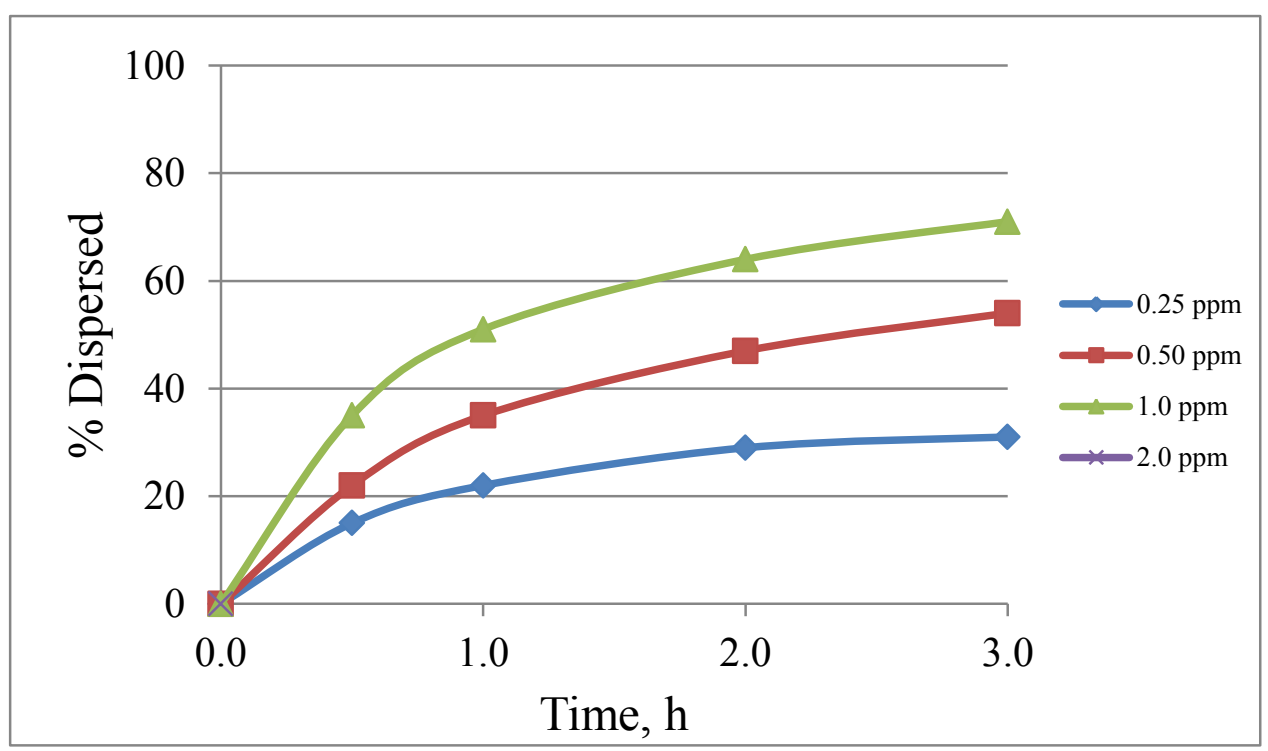

Figure 2. Iron oxide dispersion in the presence of varying concentration of $\mathrm{P} 4$ and as a function of time.

Polymer composition: The role of functional group present in polymer was investigated by conducting a series of iron oxide dispersion experiments in the presence of $1.0 \mathrm{ppm}$ polymers containing various functional groups, ionic (i.e., $-\mathrm{COOH},-\mathrm{SO}_{3} \mathrm{H}$ ) and non-ionic, i.e., (-COOR). Figure 3 presents dispersion data for various polymers, i.e., maleic acid: sulfonated styrene, P1; acrylic acid: hydroxyl propyl acrylate, P2; acrylic acid: vinyl acetate, P3; and acrylic acid:2-acrylamido-2-methylpropane sulfonic acid:sulfonated styrene, P4. It is evident that polymers containing $-\mathrm{SO}_{3} \mathrm{H}$ functional group (i.e., $\mathrm{P} 1, \mathrm{P} 4$ ) perform better than those polymers that contain non-ionic functional groups (i.e., P2, P3). Figure 3 also show the dispersion data on several homopolymers containing $-\mathrm{COOH}$ group, i.e., poly(aspartic acid), P5; poly(acrylic acid), P6; poly(methacrylic acid), P7; and carboxymethylinulin, CMI-25 (with 25\% degree of carboxylation), P8. As can be seen that all homopolymers containing a $-\mathrm{COOH}$ group (i.e., P5, P6, P7, P8) exhibit poor performance $(<30 \% D)$ compared to polymers containing two functional groups, i.e., $-\mathrm{COOH}$, $-\mathrm{SO}_{3} \mathrm{H},-\mathrm{COOR}(\mathrm{P} 1, \mathrm{P} 2, \mathrm{P} 3, \mathrm{P} 4)$. The significantly improved performance of copolymers 
over homopolymers was attributed to the more acidic character of the $-\mathrm{SO}_{3} \mathrm{H}$ group $(\mathrm{p} K \sim 3)$ in comparison with the acidity of the $-\mathrm{COOH}$ group $(\mathrm{p} K \sim 5)$ and/or steric stabilization by hydrophobic comonomers (i.e., hydroxylpropyl acrylate, vinyl acetate).

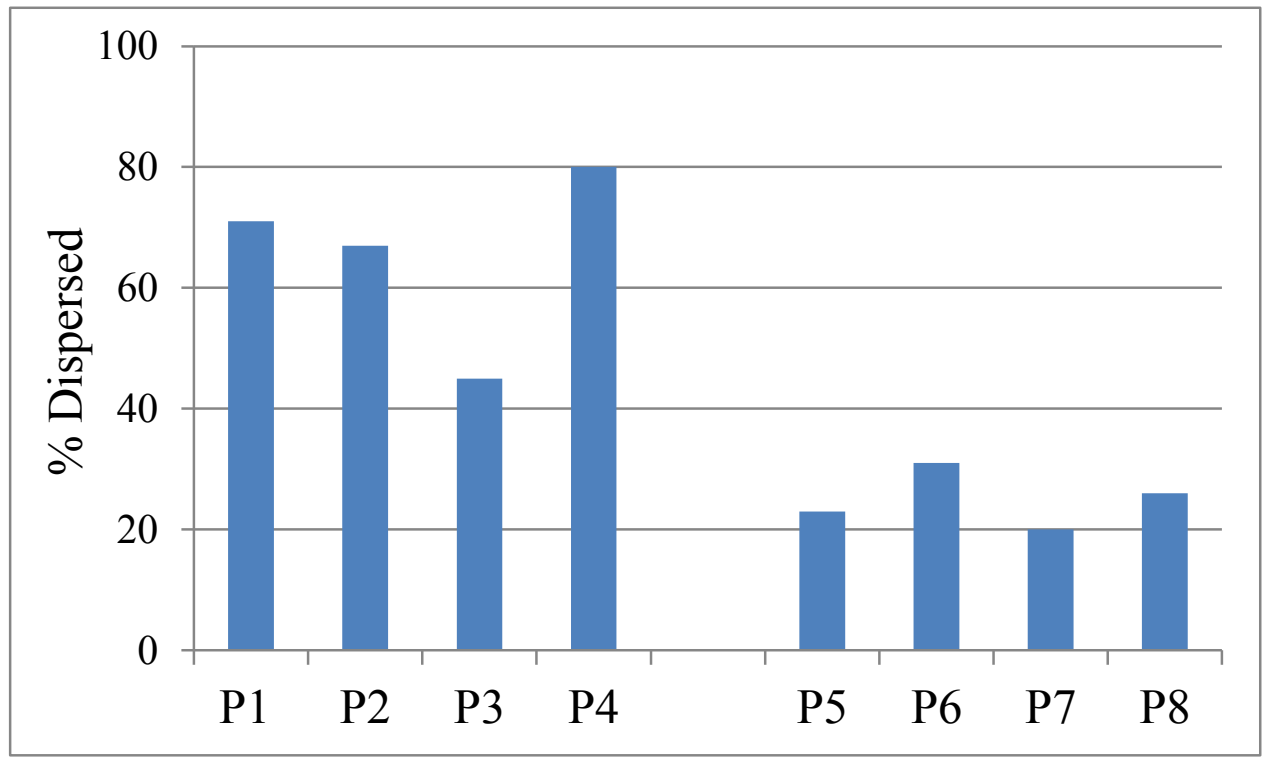

Figure 3. Percent iron oxide dispersed at 3 hour and in the presence of $1.0 \mathrm{ppm}$ homo, co-, and terpolymers.

\section{Performance of phosphonates}

As indicated in Table 1, a variety of phosphonate group containing additives are used in water treatment formulations as scale and corrosion inhibitors. To study the dispersing activity of phosphonate, a series of dispersion experiments were carried out in the presence of varying concentration of PBTC (2-phosphonobutane 1,2,4-tricarboxylic acid). Dispersion data presented in Figure 4 clearly show that $\% D$ value increases with increasing dispersion time and increasing PBTC concentration. For example, $\% D$ value obtained at $3 \mathrm{~h}$ in the presence of $0.50 \mathrm{ppm}$ PBTC is $14 \%$ compared to $19 \%$ obtained for $1.0 \mathrm{ppm}$. As illustrated in Fig. 4 , the $\% D$ values increase with increasing PBTC concentration.

To compare the performance of various phosphonates, several dispersion experiments were carried out in the presence of 1.0 and $5.0 \mathrm{ppm}$ of various phosphonates, i.e., aminotris(methylenephosphonic acid), AMP; hydroxyethylidene 1,1-diphosphonic acid, HEDP; hydroxyphosphono acetic acid; HPA; and polyamino polyether methylene phosphonic acid. It is evident from Fig. 5 that phosphonate containing additives exhibit poor performance as iron oxide dispersants. It is worth noting that whereas addition of hydroxyl and/or carboxyl group (HEDP, PBTC) does not seem to improve the dispersing ability of phosphonates, the incorporation of neutral moiety, i.e., polyether, appears to improve the performance of PAPEMP. Based on the data presented, the ranking of phosphonates as iron oxide dispersants is as follows: PAPEMP $>$ HEDP $\sim$ AMP $\sim$ PBTC $>$ HPA. Figure 5 also presents dispersion data for homo- and copolymers (P1, P6). Based on 
the data presented, the ranking of polymers and phosphonates is as follows: copolymer $>>$ $\mathrm{PAPEMP} \geq \mathrm{PAA}>\mathrm{AMP} \sim \mathrm{HEDP} \sim \mathrm{PBTC} \sim \mathrm{HPA}$.

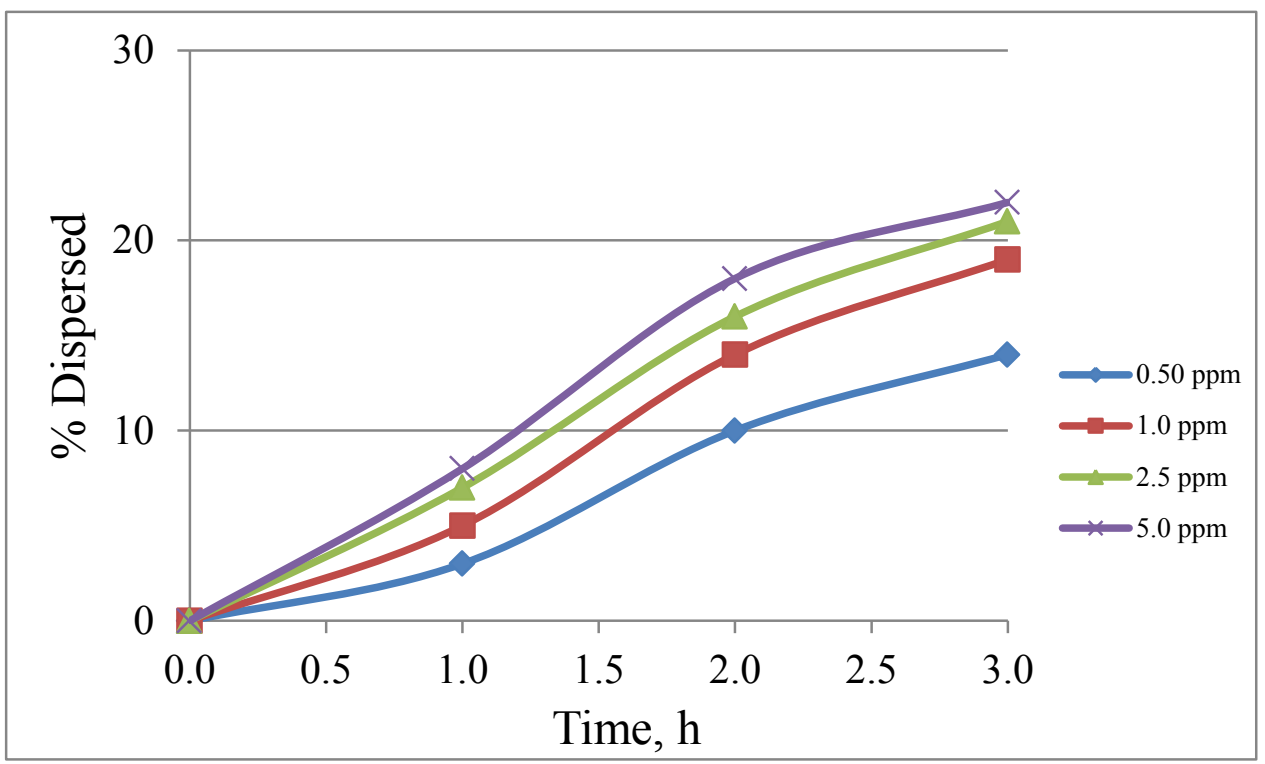

Figure 4. Iron oxide dispersion as a function of time and in the presence of varying PBTC concentrations.

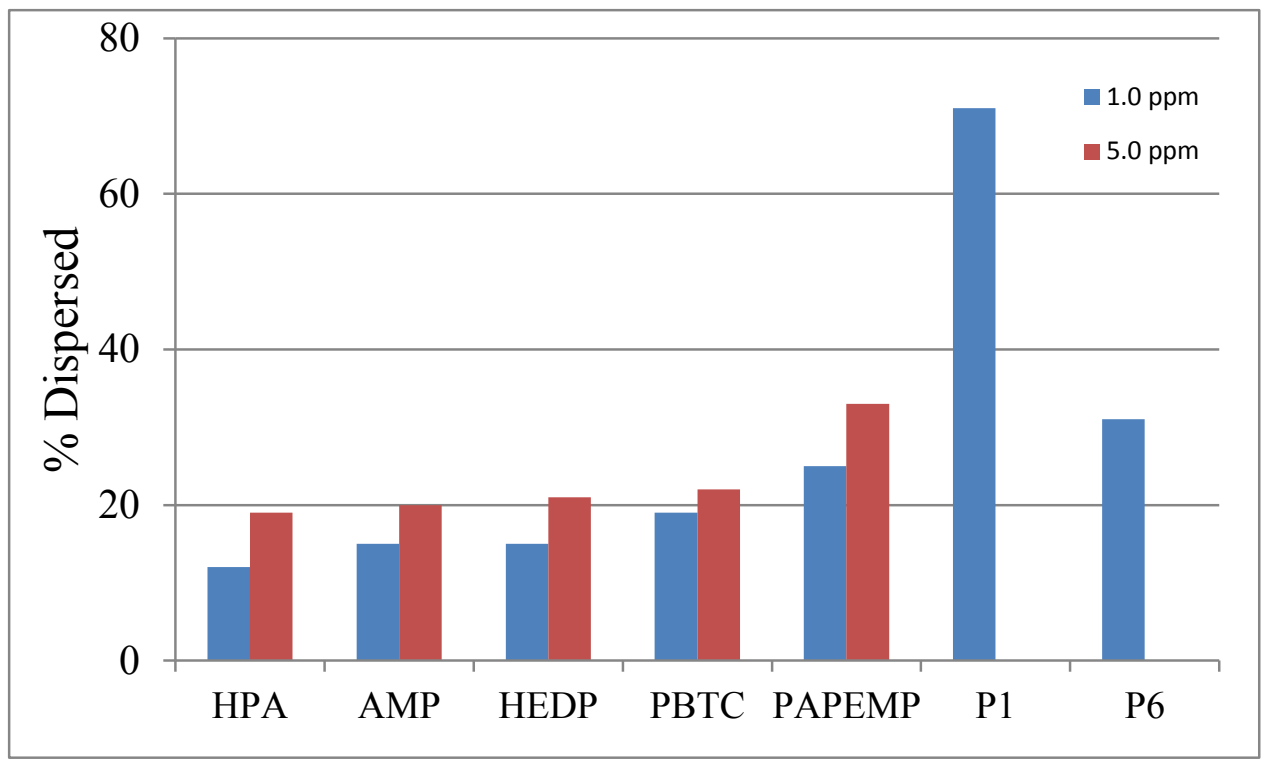

Figure 5. Iron oxide dispersion at 3 hours for phosphonates (1.0, $5.0 \mathrm{ppm})$ and $1.0 \mathrm{ppm}$ P1, P6.

The performance of phosphonates as inhibitors for calcium carbonate and calcium sulfate dihydrate (CSD) has been reported $[18,19]$. Results of these studies reveal that performance of phosphonates depends upon the concentration of phosphonates present in the scaling systems. For example, performance trend observed for $\mathrm{CaCO}_{3}$ in the presence of $5.0 \mathrm{ppm}$ phosphonates (at 180x saturation) is HEDP $\geq$ AMP $>>$ PBTC. However, at higher concentration of phosphonates (i.e., $40 \mathrm{ppm}$ ) the performance trend observed is: 
PBTC $>>$ HEDP $\geq$ AMP. The improved performance of PBTC at higher $\mathrm{CaCO}_{3}$ saturation has been attributed to better tolerance of PBTC to calcium ions. It is interesting to note that for CSD scaling system the performance trend observed for phosphonates is: AMP $>>$ PBTC $>$ HEDP $\sim$ HPA $>$ control (no phosphonate). Thus, it is clear that phosphonate performance depends on both the type of phosphonate and scaling system being inhibited.

\section{Performance of polymer/phosphonate blends}

To study the impact of phosphonate on the performance of polymers, a series of dispersion experiments were carried out in the presence of 1.0 and $5.0 \mathrm{ppm}$ PBTC (curves A, B), 1.0 ppm P4 (curve C), 1.0 ppm P4 + 1.0 ppm PBTC (curve D), and 1.0 ppm P4 +5.0 ppm PBTC (curve E). Results presented in Fig. 6 clearly show that compared to PBTC, P4 is an excellent iron oxide dispersant. For example, $\% D$ value obtained in the presence of $1.0 \mathrm{ppm} \mathrm{P4}$ at $3 \mathrm{~h}$ is $78 \%$ (curve C) compared to $19 \%$ obtained for $1.0 \mathrm{ppm}$ PBTC (curve A). It is interesting to note that increasing the PBTC concentration fivefold, i.e., from 1.0 to $5.0 \mathrm{ppm}$ results in only marginal increase (curve B) in $\% D$ value (19\% to $24 \%)$. As shown in Fig. 6, addition of 1.0 ppm of PBTC to iron oxide slurry containing 1.0 ppm P4 exhibits an antagonistic effect on the performance of $\mathrm{P} 4$ (curve D). For example, $\% D$ value obtained for P4/PBTC blend (1.0 ppm each additive) is $63 \%$ compared to $78 \%$ obtained for $1.0 \mathrm{ppm}$ P4. It is also worth noting that increasing the PBTC concentration fivefold (i.e., 1.0 to $5.0 \mathrm{ppm}$ ) in the $\mathrm{P} 4 / \mathrm{PBTC}$ blend, results in further decrease (from 63 to $58 \%$ ) in $\mathrm{P} 4$ performance (curve E). The performance of PBTC, homo- and copolymers, and PBTC/polymer blend as gypsum scale inhibitors has been reported. Results of this study reveal that PBTC/polymer blend performed better than PBTC and polymer tested alone. This observation is contrary to what is seen in the present study. Thus, it is clear that performance of phosphonate and polymer depends on both the type of inhibitor or dispersant and system being studied (precipitation or dispersion).

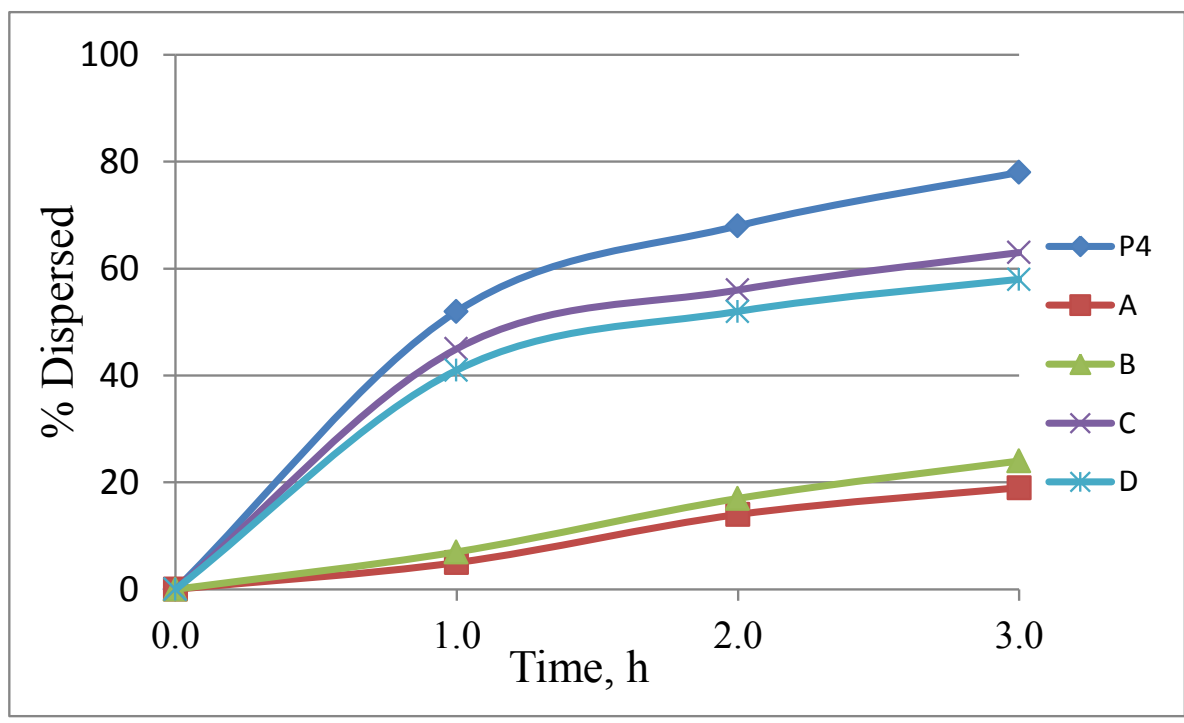

Figure 6. Iron oxide dispersion as a function of time in the presence of PBTC, P4, and P4/PBTC blend. 
Figure 7 presents dispersion data on the performance of P4 (1.0 ppm), phosphonates (1.0 ppm), and $\mathrm{P} 4 /$ phosphonate blends (1.0 ppm each additive). It is evident from Fig. 7 that addition of any phosphonate (HPA, HEDP, AMP, PAPEMP, PBTC) to iron oxide slurry containing $1.0 \mathrm{ppm} \mathrm{P4}$ exhibits antagonistic effect on the performance of $\mathrm{P} 4$. The observed antagonistic effect shown by phosphonates may be due to competitive adsorption. Under the experimental conditions used phosphonates, having low MW (200-600 Dalton) although, are poor dispersants, but are kinetically more favorable to adsorb on iron oxide particles, thus hindering the adsorption of more effective P4. It is worth noting that similar antagonistic behavior has been reported in earlier studies involving the impact of cationic additives (i.e., poly(diallyldimethyl ammonium chloride), DADMAC; cetyltrimethyl ammonium chloride, CTAM) on the performance of polymers as calcium phosphate scale inhibitor and iron oxide dispersant. The results were explained by considering the incompatibility of cationic additives with anionic polymeric scale inhibitor or dispersant thus reducing the concentration of scale inhibitor or dispersant in solution [20,21].

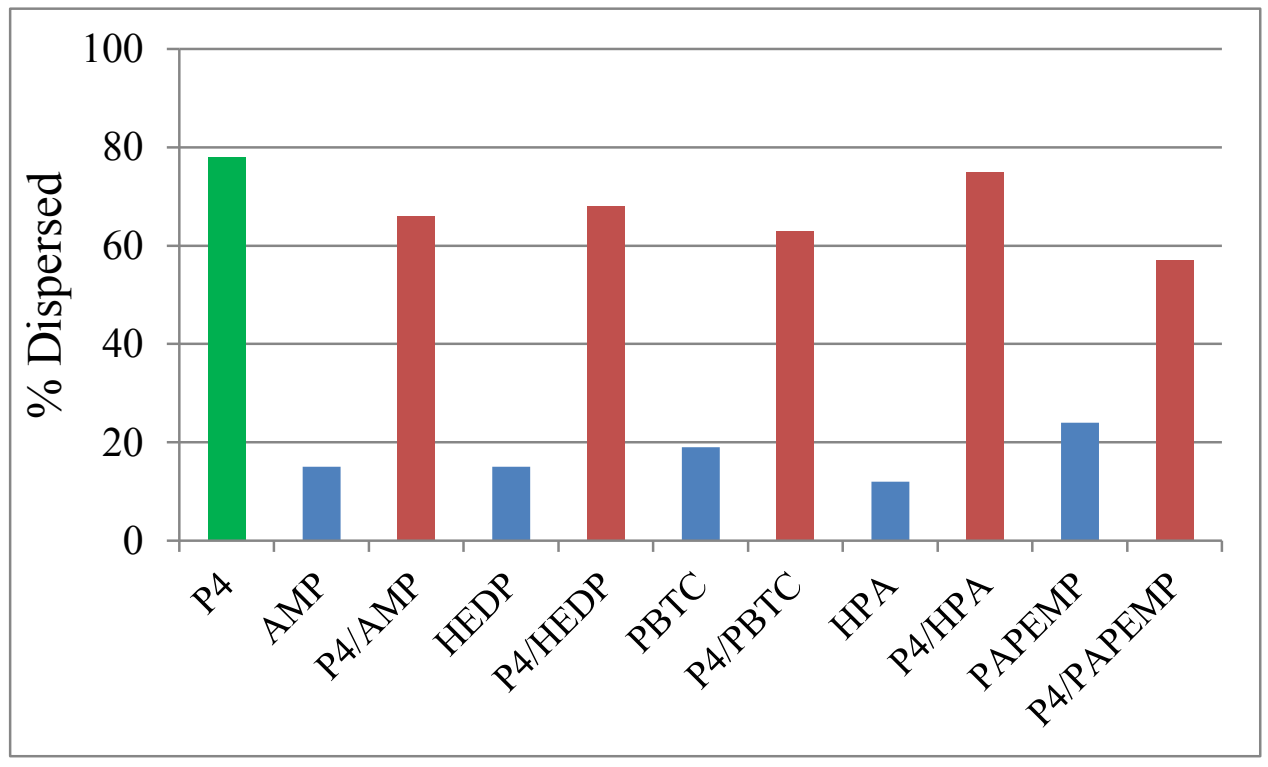

Figure 7. Percent iron oxide dispersed at 3 hour in the presence of P4, phosphonates, and P4/phosphonates.

\section{Particle size characterization by optical microscopy}

The iron oxide particles collected at the end of the experiments were also evaluated for particle morphology and size by optical microscopy. Figure 8 presents micrographs of iron oxide particles in the absence of polymer (Fig. 8A), in the presence of $1.0 \mathrm{ppm}$ of P1 (Fig. 8B), and in the presence of PBTC (Fig. 8C). It is evident from Figures 8B and 8C that whereas P1 exhibits marked effect in breaking down (or de-agglomerating) large iron oxide particles, phosphonate (i.e., PBTC) on the other hand, shows poor performance in terms of de-agglomeration of iron oxide particles. Amjad and Zuhl [22] recently studied the effect of polymers on iron oxide particle size distribution in aqueous solution. It was 
found that in the presence of polymers the iron oxide particle size distribution shifts from larger particle size $(>50 \mu)$ to smaller $(<5 \mu)$ particle size. In addition, it was also observed that heat treated co- and terpolymers show less effect on particle size distribution profiles. Thus, the results obtained in the present investigation on the dispersancy of iron oxide particles by high performance copolymer, i.e., P1, and low performance phosphonates are consistent with the changes observed in iron oxide particle size distribution in the presence of additives.

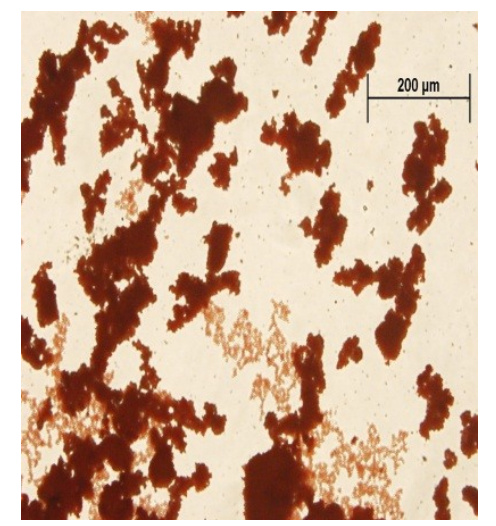

(A)

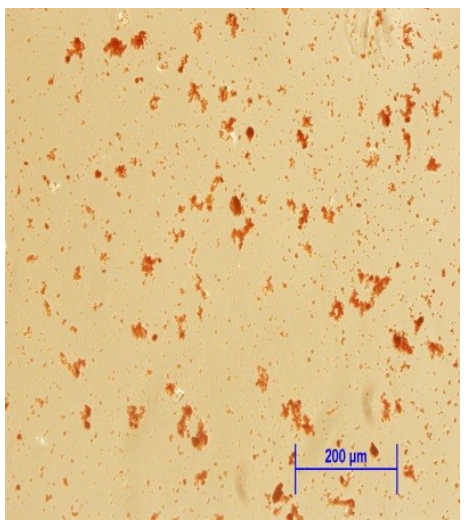

(B)

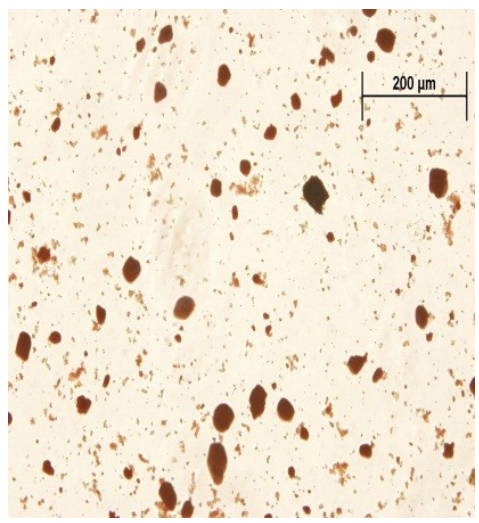

(C)

Figure 8. Optical micrographs of iron oxide particles dispersed in the absence of additive (A), in the presence of $1.0 \mathrm{ppm} \mathrm{P4}(\mathrm{B})$, and in the presence of $1.0 \mathrm{ppm}$ PBTC.

\section{Summary}

This study has shown that:

- The iron oxide dispersancy by polymeric (homo-, copolymers) and non-polymeric additives (phosphonates) increases with increasing dispersion time and additive concentrations.

- Polymer architecture exhibits significant influence in imparting dispersancy activity to polymer.

- Among the various polymers containing different function groups evaluated, co- and terpolymers containing sulfonic acid, carboxylic acid, and hydrophobic groups shows the best performance as iron oxide dispersants.

- Phosphonates, compared to co- and terpolymers exhibit poor performance in dispersing iron oxide particles in aqueous solution.

- Addition of low levels (1.0-5.0 ppm) of phosphonates to iron oxide slurries containing low levels $(1.0 \mathrm{ppm})$ terpolymer, exhibits an antagonistic influence on the performance of terpolymer in terms of de-agglomerating iron oxide particles.

- Optical microscopic study on iron oxide particle size profiles agrees with the dispersancy data obtained for phosphonates and polymers. 


\section{Acknowledgement}

The author wishes to thank Walsh University for providing the facilities to carry out this study.

\section{References}

1. R. W. Zuhl and Z. Amjad, Ch. 5 in The Science and Technology of Industrial Water Treatment, Ed. Z. Amjad, CRC Press, Boca Raton, FL, 2010.

2. J. P. Garris and C. S. Sikes, Colloids and Surfaces A: Physiochemical and Engineering Aspects, 1993, 80, 103.

3. L. Dubin and K. E. Fulks, Paper No. 84, CORROSION/84, NACE, Houston, TX, 1984.

4. D. I. Bain, G. Fan, J. Fan, H. Brugman and K. Enoch, Paper No. 02230, CORROSION/ 2002, NACE, Houston, TX, 2002.

5. Z. Amjad, Tenside Surfactants Detergents, 1999, 36, 50.

6. Z. Amjad and R. W. Zuhl, Paper presented at Association of Water Technologies Annual Convention, Reno, NV, 2010.

7. G. A. Cucil, J. MacDonald and E. B. Smyk, Paper presented at International Water Conference, Pittsburgh, PA, 1987.

8. W. F. Masler and Z. Amjad, Paper presented at CORROSION/88, NACE International, Houston, TX, 1987.

9. L. A. Perez, Chapter 17 in Calcium Phosphates in Biological and Industrial Systems, Ed. Z. Amjad, Kluwer Academic Publisher, Boston, MA, 1998.

10. Z. Amjad and J. H. Hooely, J. Colloid Interface Sci., 1985, 111, 496.

11. Z. Amjad, Tenside Surfactants Detergents, 2007, 44, 88.

12. M. Oner, O. Dogan and G. Oner, J. Crystal Growth, 1998, 186, 427.

13. P. G. Klepetsanis, P. G. Koutsoukos, G. Chitanu and A. Carpov, Chapter 10 in Water Soluble Polymers: Solution Properties and Applications, Ed. Z. Amjad, Plenum Press, New York, NY, 1998.

14. Z. Amjad and D. Morgan, Phos.Res. Bull., 2011, 25, 33.

15. Z. Amjad and R. W.Zuhl, Paper presented at Association of Water Technologies Annual Convention, Palm Springs, CA, 2005.

16. Z. Amjad, Materials Performance, 2014 (in press).

17. G. Halasz, B. Gyure, I. M. Janosi, K. G. Szabo and T. Tel, Appl. J. Phys. 2007, 75, 1092.

18. Z. Amjad and R. Zuhl, Paper presented at Association of Water Technologies Annual Convention, Nashville, TN, 2004.

19. M. Prisciandaro, E. Olivieri, A. Lancia and D. Musmarra, Ind. Eng. Chem. Res., 2009, 48, 10877.

20. Z. Amjad, Tenside Surfactants Detergents, 2011, 48, 53.

21. Z. Amjad, Desalination and Water Treatment, 2011, 36, 270.

22. Z. Amjad, Tenside Surfactants Detergents, 2006, 43, 242. 